\title{
What people want at the end of life
}

Previously published at www.cmaj.ca

$\mathrm{M}$ ost patients and families facing a terminal illness vividly recall being told about the grim prognosis Through misplaced words and actions, health professionals can unwittingly inflict pain at such a vulnerable time - not only onto patients, but also onto friends and families, ultimately poisoning the dying or grieving process.

Suboptimal end-of-life discussions may arise from many factors. Informing a patient that he or she has a terminal illness will sometimes elicit our own unresolved feelings related to death and dying, making us very uncomfortable and less willing to take on this difficult task. We may wrongly attribute low priority to such discussions, especially when we are faced with other clinical care duties. More fundamentally, we may lack insight or training to fully engage in such critical conversations.

Asking "What do dying people want?" is a good first step toward improvement. For most patients, knowing that death will not occur in the next minutes or hours is important; being reassured about timing will provide hope. Once initial anxieties are allayed, a patient's struggle will be in how to embrace life while preparing to die.

Few patients initiate conversations with words like resuscitation, inotropes or levels of care - words that are best used to communicate concepts among health professionals. Rather, patients speak of relationships with the people they love and who love them; what life means to them and how they might be remembered; the reality of death; their hope that they won't be a burden to others; their worry about how those they are leaving behind will manage without them; and a fear of the process of dying, often mixed with a belief that pain and suffering are inevitable.

So what $d o$ dying people want? In short: truth, touch and time. They want others - family, friends and physicians - to be truthful with them in all respects, whether discussing the disease process, treatment options or personal relationships. They want truth but not at the expense of reassurance and hope. Hope is not limited to escaping death. Hope for many may be in savouring final moments with the people they love and who love them. Reassurance often includes plans to try to alleviate fears of pain, suffering and loneliness. Patients also crave being touched, both physically and emotionally - perhaps to be reminded that they are still living, perhaps because family and friends often distance themselves as a disease progresses toward death. Finally, patients want time, and in most cases, there is some time. Time is key for patients to come to terms with their illness, losses and unresolved issues as well as remaining hopes, so that their minds have time to change their hearts.

To avoid iatrogenic suffering caused by poor communication, it is important that we recognize the importance of endof-life discussions. When we relegate such discussions to inexperienced members of a medical team without supervision or training, we signal that difficult communications are not important. Compassionate and skilled communication requires careful planning by experienced professionals and orchestration among all team members of the discussions, key messages and decisions.

Patients want and need a sense of connection with the person bearing bad or life-altering news, ideally through a longterm patient-provider relationship. They would prefer not to receive a rehearsed speech or pat answers delivered without context or feeling. Such detached interaction can be avoided if we first take the time to get to know our patients' hopes, fears and dreams. Such conversations should lead to an understanding of the person, not simply of the disease.

Before initial patient encounters, some introspection is vital. We would benefit from a better understanding of our own sense of mortality and of seeing dying as a physical, psychological and spiritual experience. We must come to realize that most patients as well as health care providers have anxieties about death. Given the personal commitment required, it is ideal for health professionals to reflect on end-of-life issues with skilled professionals. Long-term mentorship and role modelling will help ensure continued growth and learning.

Ushering a patient through to the end of life requires a community of care providers, because ongoing support of patients and families may require many hours of repeated discussions over several days to weeks. The benefits of such health interventions are difficult to quantify in terms of costeffectiveness, and they are often considered a luxury. Consequently, the numbers of spiritual care providers and social workers who carry much of this burden are decreasing.

Without an investment in training for all health professionals and ongoing support for palliative care, we will be "caring" for patients and families who feel abandoned, angry or overwhelmed by feelings of hopelessness. With proper support, awareness and training, all of us will be able to connect with terminally ill patients and their loved ones so that they feel sustained, rather than abandoned, at a time of great need.

\section{David Kuhl MD PhD}

Associate Professor, Department of Family Practice St. Paul's Hospital, University of British Columbia

Vancouver, BC

\section{Matthew B. Stanbrook MD PhD}

Deputy Editor, Scientific

Paul C. Hébert MD MHSc

Editor-in-Chief

CMAJ

With the editorial advisory team: Ken Flegel MDCM MSc and Noni MacDonald MD MSc

Competing interests: See www.cmaj.ca/misc/edboard.shtml for editorial advisory team statements. David Kuhl receives honoraria for speaking engagements and conferences related to end-of-life communications.

\section{CMAJ 2010. DOI:10.1503/cmaj.101201}

